\title{
Helicobacter pylori: Perturbation and restoration of gut microbiome
}

\author{
Ankita Saxena ${ }^{1}$, Asish Kumar Mukhopadhyay ${ }^{2}$ and Shoma Paul Nandi ${ }^{1 *}$ \\ ${ }^{1}$ Amity Institute of Biotechnology, Amity University, Noida, India \\ ${ }^{2}$ ICMR-National Institute of Cholera and Enteric Diseases, Kolkata, India \\ *Corresponding author (Email, spaul@amity.edu)
}

MS received 21 March 2020; accepted 10 August 2020; published online 10 September 2020

\begin{abstract}
Alternate remedies with natural products provides unlimited opportunities for new drug development. These can be either as pure compounds or as standardized set of compounds. The phytochemicals and secondary metabolites are in great demand for screening bioactive compounds and plays an important role towards drug development. Natural products have many advantages over to synthetic chemical drugs. Helicobacter pylori (H. pylori) a Gram-negative bacteria has been classified as Class I carcinogen by World Health Organization in 1994. Current treatment regimens for H. pylori is 'triple therapy' administrated for two weeks which includes a combination of two antibiotics like Amoxicillin and Clarithromycin and a proton pump inhibitor (PPI) like Lansoprazole, and for 'quadruple therapy' in addition to antibiotics and a PPI, Bismuth is used. Antibiotic resistance can be named as the main factor for failure of treatment of $H$. pylori infection. The need of the hour is to develop a herbal remedy that could combat the growth of $H$. pylori. Probiotics can also be used as 'feasible' tool for $H$. pylori infection management. Present review is an attempt to briefly discuss about the pathogenicity, genetic predisposition, perturbation of gut microbiota due to antibiotic treatment and restoration of healthy gut microbiota with phytochemicals and probiotics.
\end{abstract}

Keywords. Antibiotic resistance; Helicobacter pylori; medicinal plants; microbiome; probiotics; triple therapy

\section{Introduction}

H. pylori is a Gram-negative bacterium and causes infection in the stomach. It has the unique characteristic to thrive and survive in highly acidic environments of the stomach (Warren and Marshall 1984). The acidity of the stomach is neutralized by the enzymatic activity of the urease enzyme present in $H$. pylori. This, therefore, promotes infection of $H$. pylori. Urease protein has also been found to interact with host cells in vitro (Rokita et al. 2000), although the functional activity of this property has not been studied in vivo. $H$. pylori uses its flagella to reach epithelial cells of the stomach and penetrate the mucous lining, and easily moves from an acidic environment to a less acidic environment. The bacterium lies safely in the stomach's mucous lining. There has been a study on the role of urease surface in $H$. pylori host interaction. It was found that the surface region of this enzyme in which changes that did not affect enzymatic activity impaired bacterial persistence in a murine experimental infection model (Schoep et al. 2010). H. pylori, like any other microbe, fights against the host immunity. For example, it is recognized by toll like receptors (TLRs). TLRs are the most studied pathogen recognition receptor TLRs are secretly involved in the regulation of inflammation during the innate immune response to $H$. pylori. They represent key activators of adaptive immunity; a serious effort has been made to enlighten their role in the recognition of H. pylori and its components in multiple cell types (Smith 2014).

The exact cause of $H$. pylori spread among the population is not known. However, it is believed that fecal-oral or oral-oral route through the consumption 
of spoiled water or food is a very common cause (Brown 2000; Stefano et al. 2018). According to the epidemiological studies, water may be a major cause of H. pylori infection. Other factors responsible for infection may include poor hygiene, poor nutrition, and geographical location. H. pylori is ranked as a Class I carcinogen for gastric cancer by the World Health Organization (WHO). A large population worldwide is infected with $H$. pylori causing serious illness like a peptic ulcer or duodenum ulcer. This can further lead to gastric cancer (Taylor and Sherburne 1995). According to a study there is an estimation that $H$. pylori-positive patients have $10 \%$ to $20 \%$ lifetime risk of developing ulcer-related diseases and $1 \%$ to $2 \%$ risk for developing distal gastric cancer (Ernst and Gold 2000; Kuipers et al. 1995). The draft genome sequences of $42 \mathrm{H}$. pylori clinical strains isolated from South Indian rural populations were studied which provided further insights into the evolution and genetic makeup of Indian H. pylori strains (Shetty et al. 2018).

In 2016, it was reported that $H$. pylori infection is more persistent in developing countries like Bangladesh, India, and Pakistan as compared to developed Asian countries like China, Japan, and South Korea. But the rate of occurrence of gastric cancer is comparatively lower in Bangladesh, India, and Pakistan as compared to China, Japan, and South Korea (Zaidi 2016). Due to this reason $H$. pylori in no time became the subject of many studies. The subjects ranged from microbiological to histological, immunological to epidemiological, and ecological areas related to health (Lee 2009; Rotimi et al. 2000; Mitchell 2001; Velin and Michetti 2006). Burnring pain or ache in the abdomen, nausea, abdominal discomfort, frequent burping, and loss of appetite are the most common symptoms. Other symptoms reported are heartburn, excessive burping, bloating, and weight loss (Talley et al. 2001). For the detection of $H$. pylori, pathogen blood tests are most common. The other tests may include breath, stool, and tissue tests (endoscopy).

The most widely practised and effective treatment of H. pylori infection is a two-week treatment, the 'triple therapy'. This treatment involves a combination of antibiotics (Clarithromycin, Amoxicillin) and PPI (Omeprazole or Lansoprazole). This regimen achieves an eradication rate in only $70 \%$ cases (Malfertheiner et al. 2012). It is widely believed that antibiotic resistance is the major cause of treatment failure.

There has been a postulation in 2016 that $H$. pylori may be a part of the human microbiome. It has also been reported that due to the change of human gut microbiota, H. pylori is gradually disappearing (Yap et al. 2016) and affects human health indirectly. Therefore, in this study, the authors have hypothesized that the elimination of $H$. pylori may cause anxiety in the gastrointestinal microbiome. This can affect the health of the human host indirectly.

\section{Pathogenesis of Helicobacter pylori}

It has been more than a century since the presence of bacteria in the stomach has been identified. The researches of Nobel Prize winners Warren and Marshall (2005) during the '80s has resulted in isolation and culture of a bacteria spiral in shape which later on was named $H$. pylori. It was shown that this bacterium could colonize in the human stomach. This resulted in inducing gastric mucosal inflammation and gastritis (Marshall 2002; Marshall et al. 1985; Morris et al. 1991; Warren and Marshall 1983). The advancement of researches associated $H$. pylori with upper gastrointestinal disorders, such as peptic ulcer, gastric mucosaassociated lymphoid tissue (MALT) lymphoma, chronic gastritis, and gastric cancer (Parsonnet 1993). To investigate the seriousness of the infection by $H$. pylori, which is poorly understood, a large group of researchers is engaged in understanding the transmission into humans and its persistence in an environment which is devoid of $H$. pylori.

It is reported that the infection of $H$. pylori is increasing in developing countries (figure 1). The infection in the developing countries is approximately $25 \%$ in comparison to Western countries like America, London, and Canada (Pounder and Ng 1995). However, $85 \%$ of the population infected with $H$. pylori never reported any related complications or symptoms (Bytzer et al. 2011). On the basis of genotyping of $H$. pylori strains isolated from two study groups from West Bengal containing 52 adults suffering from duodenal ulcer. It was observed that geographic variations is associated with certain putative $H$. pylori virulence genes (Chattopadhyay et al. 2002).

There was a report that $H$. pylori infection is more likely in children and the aged population (Kusters et al. 2006). It is quite interesting to note that $H$. pylori use its flagella to reach epithelial cells of the stomach; after penetrating the mucous lining, it makes an easy way to move from an acidic environment to a less acidic environment (Amieva and El-Omar 2008). It was reported by Kao et al. (2016) that the attachment of $H$. pylori to host epithelial cells is favored by the production of Adhesin. Once H. pylori successfully colonizes, toxins get released that in turn damage the 


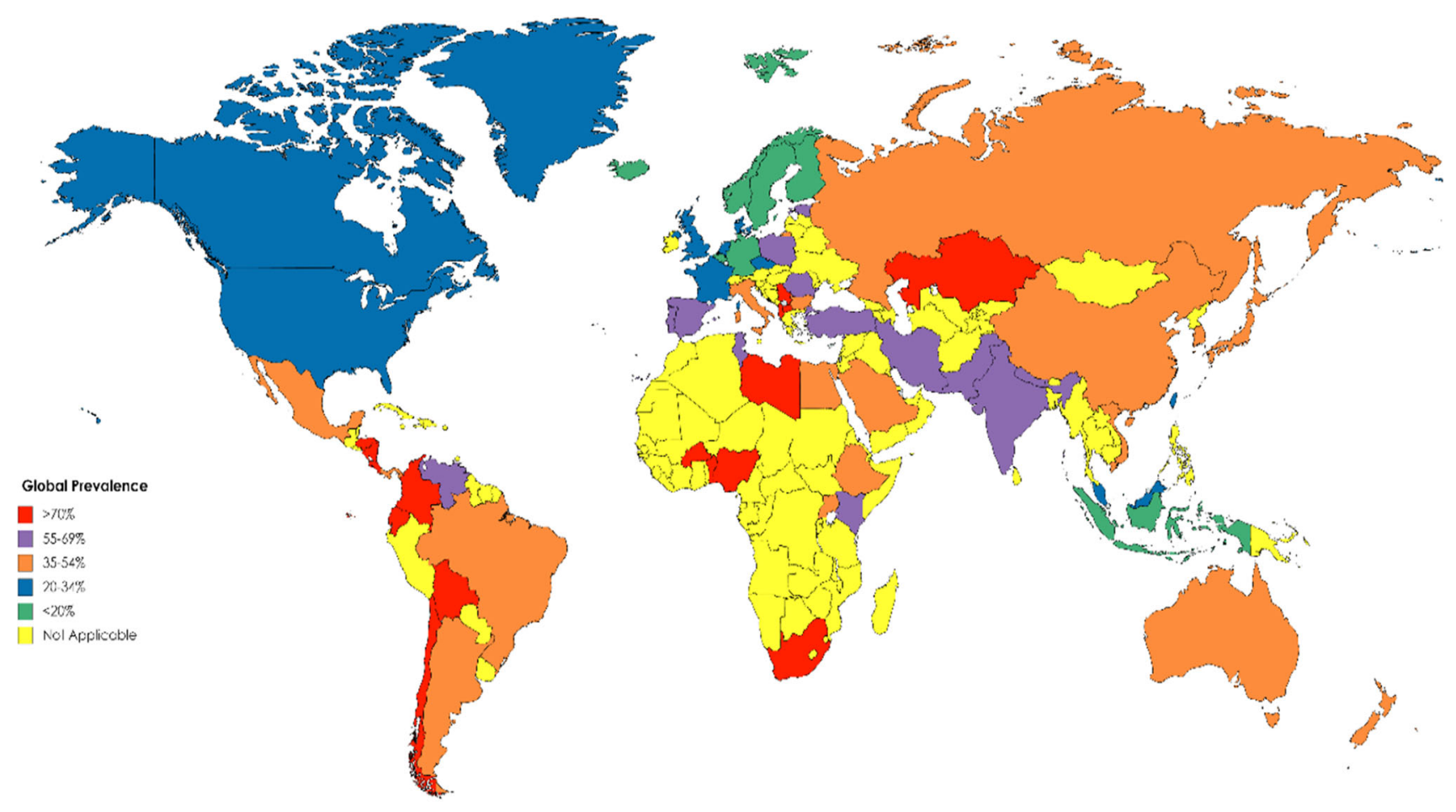

Figure 1. World map showing the spreading of H. pylori infection. Areas with colors have been used to show the prevalence. Red, $>70 \%$; purple, 55-69\%; orange, 35-54\%; blue, $21-34 \%$ and green, $<20 \%$.

host tissues. Numerous outer-membrane proteins having host-specific receptor sites act as adhesions and bind with lipids and carbohydrates available in epithelial cells. Adhesion to the epithelial cells is ensured by BabA protein that is present in the membrane of the bacteria (Ilver et al. 1998; Mahdavi et al. 2002).

Heat Shock Proteins (HSPs) have a role in H. pyloriinduced gastric ulceration (Bai et al. 2003). HSP appears to bind gastric epithelial cells and mucin via HSP 60 and to facilitate cell damage and promote carcinogenesis (Yamaguchi et al. 1998; Evans et al. 1992). H. pylori have a direct damaging effect on the mucous membrane of the stomach and duodenum, contributing to the release of lysosomal enzymes, numerous cytokines leading to the inflammatory processes in the mucosa. Lipopolysaccharide (LPS) of the outer membrane of $H$. pylori triggers an immune response of the human body resulting in the development of chronic inflammation. LPS of several strains of H. pylori express Lewis antigens. These are quite similar to those expressed by the gastric epithelial cells (Appelmelk et al. 1996). Pathogenic antibodies are induced by Lewis antigens. When there is an infection, H. pylori LPS may produce anti-Lewis antibodies that bind to bacteria. They also bind to gastric epithelium of the host, which finally leads to tissue destruction (Appelmelk et al. 1996). Lewis antigen mimicry provides endurance through immune invasion. Lewis antigens are also involved in colonization and adhesion (Appelmelk and Vandenbroucke-Grauls 2000).

The nature and seriousness of the pathological processes that are prompted by the bacterium. H. pylori at various levels are determined by a set of pathogenicity factors. It is very important for a pathogen like $H$. pylori to maintain a balance between virulence and avirulence (Kalali et al. 2014). Removal of the bacteria from the system can happen due to a strong host immune response, which can be provoked by a virulent pathogen. Modulation of virulence for successful survival in the host is one of the mechanisms developed by $H$. pylori.

\section{H. pylori and microbiome}

The genetic material of all the microbes is the microbiome. The microbiome lives on and inside the human body. The microbiome is important for human development, nutrition, and immunity. The bacteria living in and on us are not intruders, but advantageous colonizers. Disease-causing microbes accumulate over 
time. They change the gene activity and metabolic processes. This results in an abnormal immune response against substances and tissues normally present in the body (Quigley 2013). There are approximately 100 trillion microbial cells in the human microbiota. These microbial cells surmount our human cells by 10 to 1 (Savage 1977). Through the efforts of the Human Microbiome Project, the human oral and fecal microbiota have been more extensively studied than other sites in the gastrointestinal (GI) tract (Sheh and Fox 2013).

One of the major cause of public health issue is GI cancer. GI cancer is the fourth most common cancer and second leading cause of death globally (Crew and Neugut 2006). GI cancers are the end result of a complex interaction between the environment and genes. Human studies and experimental data have provided evidence that there is a role of microbiota in cancer development (Karpinski 2019; Compare and Nardone 2011; Bhatt et al. 2017). There are many factors that play a role in this, such as antibiotic treatment, diet, or lifestyle. Due to the reasonable stability of our microbiome, it is capable of halting or at least decreasing the progress of cancer. Chronic inflammation influencing the genomic stability of host cells is a crucial event in carcinogenesis. This leads to the activation of immune mechanisms (Tozun and Vardareli 2016).

The development of gastric malignancies may be influenced by the microbiome. There was an assumption that the adverse microbial community could not be supported by the gastric niche. The acidic environment of the stomach and low levels of the bacteria cultured were the reasons cited (Turnbaugh et al. 2007). A complex microbiota has been discovered, that lies in the human stomach with the power of induction of disease. The discovery of the complex microbiota was due to the advancements in DNA sequencing of conserved ribosomal genes, computational methods, and phylogenetic analysis.

The human gut microbiome is important for the maintenance of human health. It plays an intrinsic role in the absorption of nutrients, energy metabolism, and defense against pathogens attack (Gevers et al. 2012; Nicholson et al. 2012; Lozupone et al. 2012). This microbiome exists within a delicate balance. If this balance is modified, then the microbiota becomes dysbiotic. This further contributes to diverted pro-inflammatory immune responses, perceptivity to invading pathogens, and initiation of disease processes, including cancer (Schwabe and Jobin 2013). This leads to the pathogenesis of GI cancer in the esophagus
(Yamamura et al. 2016) and colon (Candela et al. 2014; Sears and Garrett 2014). Special bacterial species like Fusobacterium nucleatum and Escherichia coli are associated with the development of colorectal cancer (Castellarin et al. 2012; Bonnet et al. 2014) and gastric cancer (H. pylori) (Wang 2014). Figure 2 shows the primary phyla of the gastric microbiota based on the status of $H$. pylori.

The prevalence of $H$. pylori globally is high in spite of its gradually declining prevalence in many regions. The continuous evolution of clinical aspects of $H$. pylori infection and therapeutic management requires unceasing adaptation (Malfertheiner et al. 2018).

Besides bacterial resistance and the occurrence of detrimental events, there are many other factors that contribute towards the failure of $H$. pylori treatment. There are certain probiotic strains that have shown growth inhibition of $H$. pylori. The side effects that occur due to antibiotic therapy have been reduced by certain probiotic strains. This increases the $H$. pylori eradication rate (Homan and Orel 2015).

\section{Genetic predisposition}

According to United States National Library of Medicine, the distinguished genetic characteristic which has an effect on the probable phenotypic development of an individual organism within a population or a species under the domination of environmental conditions is genetic predisposition. The clinical outcomes in the $H$. pylori infection may be due to genetic factors and environmental conditions. The genetic factors include both host genetic predisposition to infection as well as genetic differences in H. pylori strains (Graham et al. 1994).

There are various treatments available in the global market of medicines to combat $H$. pylori infection. Triple therapy and sequential therapy had a success rate of $75 \%$ to $90 \%$; however, in this approach, bacteria remain oscillating between a non-replicative state (microorganism becomes resistant to antibiotics) and a replicative state (microorganism remains susceptible to antibiotics). If the $\mathrm{pH}$ is between 4.0 and 6.0, the bacteria cannot enter the replicative cycle. Eradication of the microorganisms becomes difficult when they assume the resistant state (Egan et al. 2007; Wu et al. 2012; Kuol et al. 2013). The individuals may become vulnerable to the development of gastric cancer since H. pylori are the etiologic factor involved in the majority of the patients with peptic ulcer disease (Nagahata et al. 1996). In the human stomach, the $H$. 


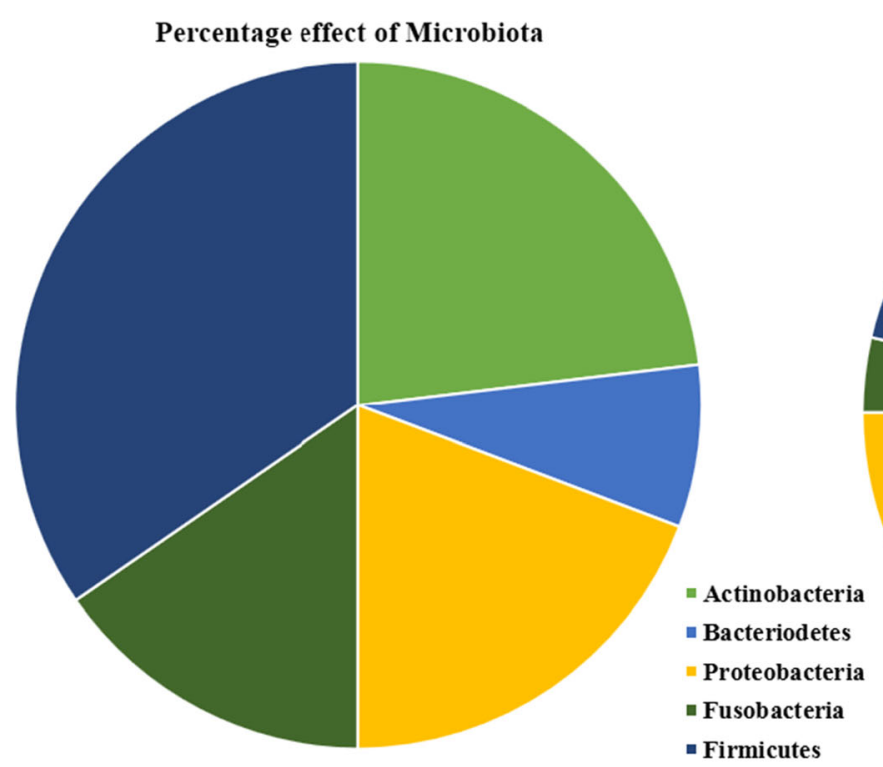

H. pylori Negative

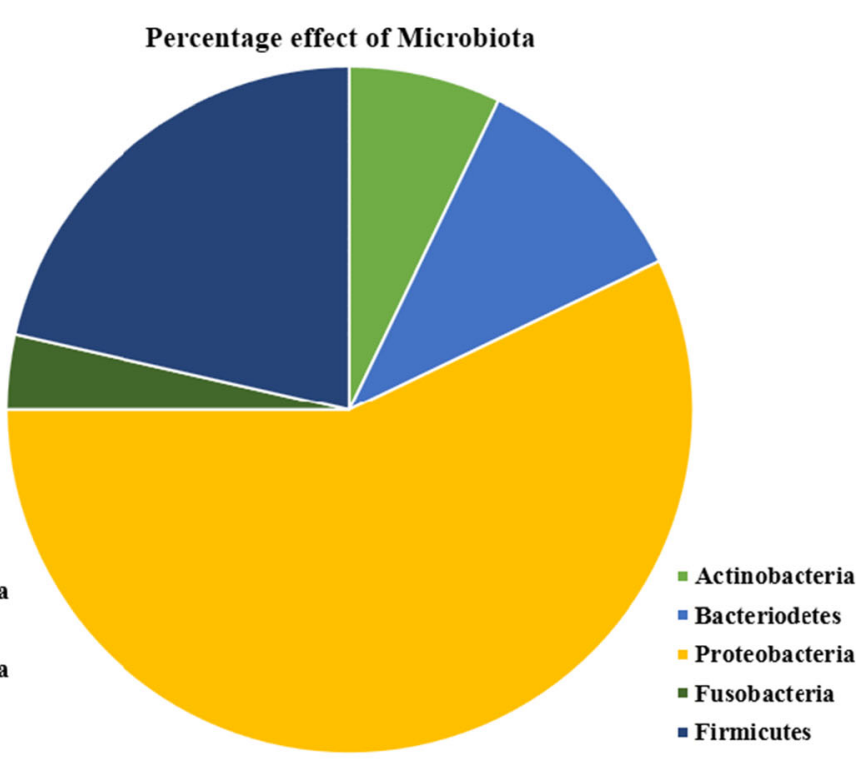

H. pylori Positive

Figure 2. Effect of $H$. pylori on microbiota. H. pylori-negative people have a more difficult and divergent microbiota as compared with $H$. pylori-positive patients (as adapted from Noto and Peek 2017).

pylori colonize. The mode of $H$. pylori transmission is uncertain, but it can be assumed to be spread from person to person. This can be via the fecal-oral route. The socio-economic status seems to be inversely related to the widespread presence of $H$. pylori in adults (Graham 1991). Water is also thought to be a reservoir for transmission of $H$. pylori (Bellack et al. 2006).

The major risk factor accepted for gastric cancer development is infection with $H$. pylori. The risk of a carcinogenic effect is increased because of the damage to the mucosal barrier. This is due to the H. pyloriinduced inflammation. Due to the genetic disposition of the bacterial strain and the host, there is an increase in the capability of gastric cancer formation. Genetic variance of VacA (Vacuolating Cytotoxin A) and CagA (Cytotoxin Associated Gene A) bacterial proteins is associated with higher gastric cancer risk. Even polymorphism and genetic changes in the host gene coding for interleukins (IL 1 $\beta$, IL 8) have also been perceived. It is astounding that $H$. pylori are able to survive in most of the hosts without activating a strong host immune system (Bornschein and Malfertheiner 2014). Immunogenic virulent factors $\mathrm{Cag} \mathrm{A}$ and $\mathrm{VacA}$ cannot deter $H$. pylori from doing so. An additional aspect of this interaction is due to the fact that $H$. pylori strains are genetically diverse. One host can have more than one strain. It was seen that the effects of methylation differ from strain to strain. This in turn creates more variability in the habitat. $H$. pylori are said to have a limited host range and small genome coding for very few numbers of regulatory proteins. This controls the gene expression by differential methylation. Approximately $50 \%$ of all $H$. pylori strains secrete VacA. It is not essential for the growth of $H$. pylori, in vitro (Cover and Blaser 1992). VacA was reported to significantly contribute to gastric colonization by $H$. pylori in rodents. VacA has been reported to play an important role in the pathogenesis of peptic ulceration and gastric cancer (Salama et al. 2001).

The widespread presence of $H$. pylori infection is much higher in India, as compared to most Western countries. Almost all infected patients were carrying multiple strains of $H$. pylori (Suerbaum and Josenhans 2007). This diversity of the $H$. pylori population is clinically very important. The appropriate target of virulence gene or its allele may be overseen if the practice of characterization single isolate from infected individuals is done. The uneven distribution of $H$. pylori throughout the gastric mucosa should be given importance. This is because different genotypes may be prevalent at different sites. A study indicates including multiple colonies from a single host. This can be either from single or different sites in the case of multi ulceration (Patra et al. 2012).

In the pathogenesis of gastric ulcers, the role of TNF$\alpha$ (tumor necrotic factor) is well established. TNF- $\alpha$ is a cytokine and plays an important role in gastric ulcer formation (Lychkova et al. 2010). It initiates the 
inflammatory process by stimulation and migration of leukocytes into the inflammatory sites. CagA is a highly immunogenic protein encoded by the cagA gene. This CagA was linked to the virulent property of H. pylori. This gene is a marker for the presence of a genomic PAI (Pathogenicity Island) (Silveira et al. 2005). Patients with peptic ulcers or gastric cancer have strains lacking the cagPAI, but with low frequencies. CagA affects cell shape, disturbs cell junctional activity, increases cell motility, and is responsible for gastric ulcers and gastric cancers (Buti et al. 2011). All this happens after the translocation into the host cell. $H$. pylori acid resistance is due to the urease enzyme. This enzyme converts urea into ammonia and carbamate, which spontaneously breaks down into another ammonia molecule and carbon dioxide (Burne and Chen 2000). Ammonia, which is basic in nature, then neutralizes acid in the stomach environment making it sanatorium for H. pylori (Pandey et al. 2010).

Even though the urease activity is present in all $H$. pylori isolates, the levels of urease activity differ remarkably between strains. The urease activity is dependent on the growth conditions (Konturek et al. 2001; Lloyd and Soll 1994). The proteins encoded by the cagPAI are responsible for the introduction of secretion of IL-8, forming the support and remodeling the surface of epithelial cells. H. pylori can be divided into two types: Type I that expresses CagA+ associated with VacA, whereas Type II does not express CagA but is associated with VacA. The ability to induce large cytoplasmic vacuoles in the eukaryotic cells is that of VacA. This can lead to cell death (Darini 2004). The transfer of CagA oncoprotein to the host cytoplasm is done by Type IVSecretion System (T4SS). Here it becomes phosphorylated and affects various cellular processes (Backert and Selbach 2008). It is considered to be the direct contact of T4SS with the epithelial cell membrane. This process is believed to be majorly responsible for the induction of IL- 8 and other host immune responses. The $\alpha 5 \beta 1$ epithelial integrin has been specified as one of the host receptors involved in this activity. The expression of these integrins is limited to the basolateral membrane (Kwok et al. 2007). The study of H. pylori-host cellular interactions could be facilitated by a monolayer in vitro model of epithelial cells having narrow junction integrity and measurable barrier function. A detailed examination of the apical and basolateral molecular events that occur during the infection by the pathogen can be studied (Fiorentino et al. 2013). The occurrence of monocholaramine has been related to the gastric injuries detected in the presence of $H$. pylori (Weeks and Sachs 2001). This derivative creates large amounts of ammonia, which in turn activates neutrophils that produce hypochlorous acid. This acid reacts with the amino acid taurine, in turn forming taurine-chloramine (Suzuki et al. 1998; Lapenna and Curccurollo 1996). Currently, the major virulence factors of the pathogens are urease, VacA, and CagA gene products.

It is widely believed that during infection, there is an expansion in gastrin and gastric acid secretion. This has caught the eye of many researchers from various scientific fields seeking therapeutic replacements. These alternatives may behave favorably if provided with all the factors involved (Gürbüz et al. 2002). The main habitat of $H$. pylori is considered to be gastric mucosa. This is because the bacterium survives in an acidic medium. Gastric colonization and $H$. pylori survival require the catalytic power of proteases. The serine protease HtrA (High-temperature requirement A) is considered to be important for the survival of the bacteria since it has been found in most infected individuals. Lysosomal cathepsins and metalloproteases are abundantly found during the early stages of $H$. pylorimediated pathogenesis. Therefore, this class of protease enzymes may play a functional role in stomach cancer (Kim et al. 2013).

\section{Combating $H$. pylori infection}

\subsection{Drugs}

H. pylori infection is a severe disease and has been difficult to cure. The treatment schedule comprises of at least two high-dose antibiotics (Clarithromycin + Amoxicillin/Metronidazole) plus a proton pump inhibitor (PPI), twice daily for a 7- to 10-day period (Lind et al. 1996). In fact, it is a matter of concern that there is an emergence of resistance to antibiotics and is increasing day by day. This is thrusting a challenge to cure the diseases. Treatment failure is due to antibiotic resistance. In the near future, the development of novel drugs against infection is needed for more effective control of these diseases. Researchers are trying to develop several alternatives to cure $H$. pylori infection. The management of $H$. pylori infection is therefore very important. Challenges range from patient information to motivation of the doctors to antimicrobial treatment and patient compliance. The treatments available are drugs which have their own side-effects and the newer approach of medicinal plants along with probiotics (figure 3 ). An effective vaccine that could prevent and/or cure the infection, or modify 


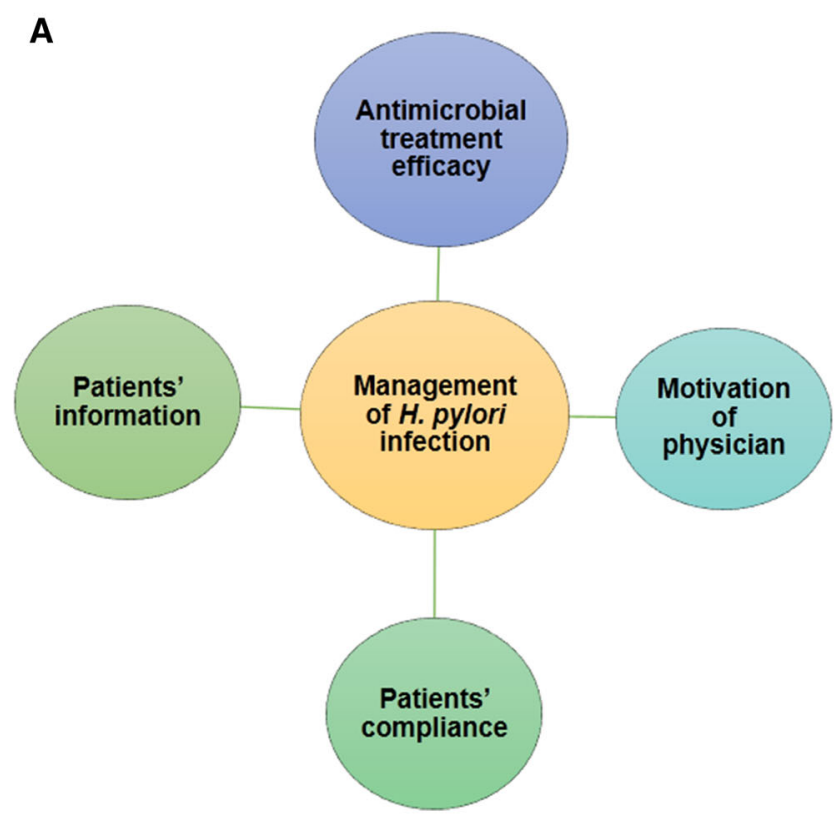

Challenges
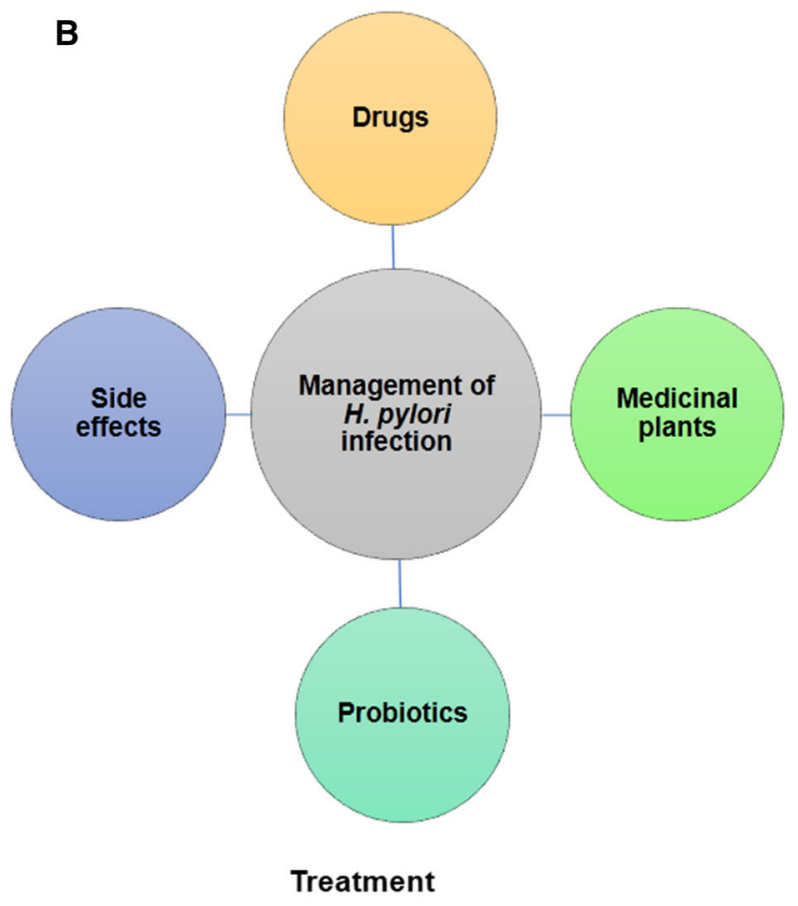

Figure 3. Management of H. pylori infection. (A) The challenges involved in H. pylori infection. (B) Treatment required in H. pylori infection.

the interactions of the host-pathogens in a way that prevents disease progression. There have been continuous efforts to obtain a vaccine against $H$. pylori. This vaccine development has been focused on finding the best route of delivery. In addition it would find adjuvants and antigens that favor the induction of protective immunity (Czinn and Blanchard 2011). The development of a secure and effective vaccine for human use is still not available, although some encouraging results have been obtained in animal models.

Another curative approach is to find an inhibitor of enzymes that has a crucial role in the life cycle of the pathogen and it should affect only the prokaryotes or lower eukaryotes, otherwise it might have side-effects for humans. One such example is Shikimate kinase (EC 2.7.1.71). This is the fifth enzyme of the pathway and catalyzes the specific phosphorylation of the 3-hydroxyl group of shikimic acid in the presence of adenosine triphosphate (ATP). Shikimate kinase represents a potent target for the development of new antimicrobial agents (Coggins et al. 2003; Herrmann and Weaver 1999; Ridley 1998; Roberts et al. 1998).

\subsection{Medicinal plants: the upcoming weapon}

In many South Asian countries like India, Nepal, Pakistan, and Bangladesh, spices are used in the traditional system of medicine due to the presence of medicinal values. These dietary spices are also prescribed for the treatment of GI diseases (Zaidi et al. 2009; Zaidi and Sugiyama 2013). Studies have shown the protective effects of spices and medicinal plants against numerous diseases including $H$. pylori and GI disorders. The bactericidal and anti-adhesive activities of culinary herbs against $H$. pylori from Malaysia have also been reported (Gilani and Rahman 2005; O’Mahony et al. 2005). There were reports from Pakistan of the potential effect of commonly used spices and medicinal plants on $H$. pylori and its associated pathogenesis (Zaidi et al. 2009).

Anti-H. pylori compounds act as an inhibitor of enzymes (DNA gyrase, $N$-acetyltransferase, urease, dihydrofolate reductase, and myeloperoxidase) and high redox potential, adhesive activities and hydrophilic/hydrophobic natures of compounds (Wang 2014). Many natural products have anti- $H$. pylori-induced inflammation activity, such as suppression of nuclear factor- $\kappa \mathrm{B}$, activation of mitogen-activated protein kinase pathway, and oxidative stress inhibition (Chatterjee et al. 2012; Takeuchi et al. 2014). These products include apigenin, quercetin, tea products, carotenoids-rich algae, garlic extract, finger-root extract, and polyphenol from apple peel. Numerous medicinal plant products possess anti- $H$. pylori activity, along with an anti-H. pylori-induced gastric 
inflammatory effect. These plant products have shown promising potential as pharmaceutical candidates for $H$. pylori eradication and prevention of $H$. pylori-induced gastric disease (Wang 2014).

Table 1 illustrates anti-H. pylori activities of Syzygium aromaticum (clove), Emblica officinalis (amla), Allium sativum (garlic), Aloe vera (aloe), honey, and Curcumin longa (curcumin).

\subsection{Probiotics}

A probiotic is defined as a 'live microbial organism which, when ingested, beneficially affects human health, including amelioration or prevention of specific disease state' (Fuller 1992). The probiotic microorganism can be used as a 'feasible' tool for $H$. pylori infection management. Lactic acid bacteria, particularly Lactobacillus species and Bifidobacterium species, have been the most studied probiotics. Other organisms that are used as probiotics in humans include Escherichia coli, species of Streptococcus, Enterococcus, Bacteroides, Bacillus, and Propionibacterium (Rolfe 2000; Montrose and Floch 2005; Gill and Guarner 2004; Suvarna and Boby 2005). There is a recent study that has focused on the use of yeast as a probiotic to reduce GI tract disorders. This study shows how yeast can be an integral part of human microbiome as probiotics. Saccharomyces boulardii is commonly used to reduce GI tract ailments, since is it well characterized probiotic yeast (Sen and Mansell 2020). Supplementing probiotics have shown to be useful in several gastrointestinal diseases, such as irritable bowel syndrome, inflammatory bowel disease, improving the $H$. pylori eradication rates, preventing or decreasing antibiotic-associated diarrhea, and lowering the taste disturbance incidences. Probiotic supplementation may partially reinstitute physiological microecology in the intestine. This in addition provides one alternative therapy, because these bacteria have been reported to possess antimicrobial properties against pathogens. (Servin and Coconier 2003). The effect of the supernatant of Lactobacillus acidophilus (L. acidophilus) culture on the growth of $H$. pylori isolates was tested. These $H$. pylori isolates have been recovered from antral biopsies. It was found that the growth of $H$. pylori was inhibited by isolates. It was also hypothesized that all of this depends on the secretion of lactic acid from the Lactobacillus (Bhatia et al. 1989). It was in 1989 that the first positive in vitro result appeared. This was an opportunity to use probiotic species in $H$. pylori therapy. The possibility to reduce antibiotic-
Table 1. Anti- H. pylori properties of some selected plants and natural products

Sr.

No. Name of the plant Activities/Uses

1. Syzygium aromaticum 1) Inhibited the growth of $H$. (Clove) pylori (Balch and Balch 2000; Kim et al. 1998)

2) Antimicrobial properties (Nazrul et al. 2010)



2. Emblica officinalis (Amla) 1) Antimicrobial activity against

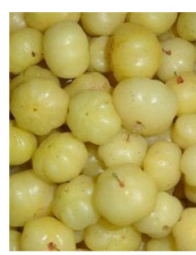

H. pylori has been reported (Rajkumar et al. 2014)

3. Allium sativum (Garlic)

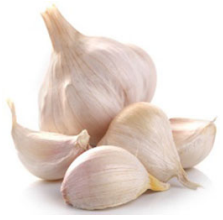

4. Aloe vera (Aloe vera)

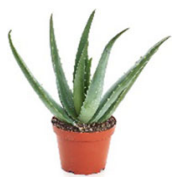

5. Honey

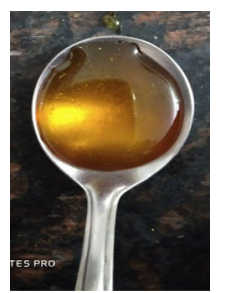

6. Curcuma longa (Curcumin)

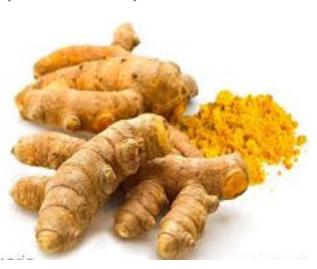

1) Anti-inflammatory (Sarkar et al. 2016)

2) Anti-oxidant (Sarkar et al. 2016)

3) Anti-cancer (Sarkar et al. 2016)

4) Anti-proliferative (Sarkar et al. 2016)

5) Anti-microbial (Sarkar et al. 2016)

6) Reduces gastric damage due to H. pylori infection (De et al. 2009) 
associated side-effects is worthy of getting attention and needs larger trials to be confirmed. Future trials should address in particular the type of patient (asymptomatic volunteers, symptomatic patients), and choice of probiotic strain(s). This has prompted investigators to study the possibility of reducing antibiotic-associated side-effects.

To diminish the quantity of $H$. pylori by selective bacterial-bacterial cell interaction, an effective and newer method for resisting stomach microbes, was undertaken. It was thought to be an efficacious method to fight the pathogens of the stomach. The most specific binding opponent to $H$. pylori among 700 wild-type strains of Lactobacillus species was Lactobacillus reuteri (L. reuteri) DSM17648. The strain DSM17648 co-aggregates the pathogen both in vivo and in vitro. A specific co-aggregation occurs between different strains of $H$. pylori and L. reuteri DSM17648 but not with Camylobacter jejuni or other intestinal and oral bacteria (Holz et al. 2015; Buckley et al. 2018).

Probiotics have shown promising results in biological experiments; however, negligible studies have been done to determine their effect on humans. It is critical to identify the precise molecular mechanism that determines the action of probiotics on health and disease conditions (Qureshi et al. 2019). Therefore, it is important to know the mechanism probiotics use to oppose $H$. pylori infection.

The effect of probiotics on H. pylori infection, improvement in H. pylori gastritis, reduction in bacterial colonization, and achievement of complete eradication has been reviewed in in vitro clinical trials (Patel et al. 2013; Song et al. 2018; Ahmad et al. 2013). There was a study conducted on 66 children aged between 3 and 14 years infected with $H$. pylori. They were divided into two groups: Group A received antibiotic + PPI + placebo and Group B received antibiotic + PPI + probiotic. The probiotic was a combination of Lactobacillus bulgaricus, L. acidophilus, L. casei, L. rhamnosus, Bifidobacterium infantis, B. breve, and Streptococcus thermophilus. Both groups A and B demonstrated improvement in clinical symptoms after treatment. Group B, which was given probiotic treatment in addition to antibiotic and PPI, showed greater significant eradication rate (Khodadad et al. 2013). The human gastrointestinal tract is a complex and combative environment. It is unconvincing that a single probiotic bacterial strain will have the magnitude to influence the microbial ecology of the host. In another instance, a study was conducted on 14 $H$. pylori-infected patients. They were treated with $L$. acidophilus. The eradication rate of $H$. pylori increased considerably, while the colonization rate of $H$. pylori decreased (Mrda et al 1998). Even if the single probiotic strain has the enormity to influence the microbial ecology of the host, it may reduce the chances of the occurrence of diarrhea, lactose intolerance, levels of blood cholesterol, mucosal immune responses, and the induction of cancer (Dunne et al. 1999). Probiotics mimic the function of the human microbiota, hence act both in reducing the side-effects and also in improving the efficiency of antibiotics. Phytotherapy and bacteriophage therapy have shown great potential as an alternative to antibiotics (Vitor and Vale 2011).

Medicinal plant products are usually selected with a protracted history of their use against diseases associated with stomach infection. Such herbs come from the folk medicine of each country. Studies through many years have revealed that many phytomedicine products have an anti-H. pylori activity and gastroprotective action. Although the mechanism of action is not understood completely yet, the current knowledge acts as a bridge between instrumental action of herbs with inhibition of essential enzymes of $H$. pylori, attenuation of inflammation, and modulation of the host immune system (Vale and Oleastro 2014).

Phage therapy is extensively being relooked as an alternative to antibiotics (Lin et al. 2017). The phage display approach is used to select peptides that specifically bound $H$. pylori urease holoenzyme and inhibited its enzymatic activity in vitro (Houimel et al. 2001). A combinatorial library and two newly constructed random peptide libraries were used to identify two peptides that specifically inhibited the activity of H. pylori urease. A study identified four single-chain Fv antibody fragments binding to $H$. pylori urease. The peptide sequences inhibited single-chain $\mathrm{Fv}$ binding to $H$. pylori urease, and the authors suggested they could be used in a vaccination strategy (Mader et al. 1997). There is limited knowledge of the use of phages in the treatment of $H$. pylori. Recently, there has been a study of a temperate phage of $H$. pylori, induced by ultraviolet (Vale et al. 2008). This along with the sequences of complete (Lehours et al. 2011; Uchiyama et al. 2012) and remnant prophages provided whole genome sequencing of $H$. pylori strains.

Probiotics were found to be useful in several gastrointestinal diseases. There are reports that have shown the defeat of the bacterium by the eradication rate of probiotics' monotherapy. Probiotics compete with $H$. pylori for host surface receptors, thereby inhibiting its adhesion to epithelial cells. It has also been demonstrated that probiotics could hamper $H$. pylori urease activity. On these basis, since probiotic 
administration does not carry the risk of antibiotic resistance, it could represent an optimal strategy in selected cases (Losurdo et al. 2018).

Pre-treatment of L. plantarum ZDY 2013 played a pivotal role in preventing gastric mucosal inflammation and gastric microbiota alteration induced by $H$. pylori infection. The selective modulation in gastric microbiota posed by this interference indicated that targeting gastric microbiota through oral administration of probiotics might be an alternative strategy to prevent infection caused by H. pylori (Pan et al. 2016).

A study was performed that showed that the intestinal microbiota is composed mainly of Gramnegative anaerobic bacilli. These bacilli live in the colon microenvironment with Bacteroides and $\mathrm{Fu}$ sobacterium as the main genera (Torres 2017). The interest for the possible interactions between the intestinal microbiota and other important pathogens, such as $H$. pylori, has grown immensely (Parker 2016).

Some serious changes in the gastric microenvironment is produced by $H$. pylori infection. This influences the composition of gastric microbiota. Large intestinal microbiota changes might have close relations with it. This action could trigger important modifications in the homeostatic functions exerted by gut commensals. Further, this would lead to a new gastrointestinal balance. Simultaneously the strategies used to eradicate $H$. pylori can modulate this physiological symbiosis, but can be also conversely affected by its properties (Lopetuso et al. 2018)

The critical involvement of human gut microbiota in human health and a slight alteration induces a dysbiotic situation that develops gastric cancer. Promoting health and preventing disease is explicitly functioned by the host microbiota. The dysbiosis contributes to inflammation, susceptibility to pathogens, and diseases (Noto and Peek 2017). Although there have been great advances in research to understand the complex interaction between $H$. pylori and the gastric microbiota in the development of gastric inflammation and cancer, detailed studies are still needed. Such a study should be done in a well-defined human population, in order to compare differences in the microbiota of $H$. pylori-infected patients with and without neoplastic lesions (Joo 2017).

The currently prescribed treatment for $H$. pylori infection instigates long-term disturbances in the intestinal microbiota. The combination of the probiotics appeared to result in changes in the microbiota which are minor (Myllyluoma et al. 2007). Therefore, following probiotic supplementation with antibiotic therapy can be an effective way to cure infection caused by $H$. pylori.

The clinical implications are partially understood, since many studies have described $H$. pylori-dependent gut microbiota alterations. In addition to this, the mechanism of actions that sustain these processes is also not clear. This represents a undisputed challenge for future research projects which need to understand the role played by viruses, parasites, yeasts, fungi, as well as H. pylori.

\section{Conclusion}

Antibiotic therapy has a limitation mainly due to antibiotic resistance to eradicate $H$. pylori. Therefore, it becomes very pertinent to look for alternatives to fight against $H$. pylori infection. According to the research in last few decades, it clearly illustrates the tremendous progress in the pathogenicity, involvement of microbiome and genetic predisposition in understanding the severity of gastric inflammation and gastric cancer produced by $H$. pylori. The role of $H$. pylori virulence genes, such as CagA and VacA, in the development of gastric diseases is now being extensively studied. A few studies have been carried out on the role of the membrane vesicles, molecular and functional aspects, role of interaction of HopQ adhesion and HSP. The study on involvement of virulence factors in $H$. pylori pathogenesis will be highly beneficial for vaccine development and to find an alternative therapy. It appears that combination therapy consisting of phytochemicals and probiotics is a promising choice. Phytochemicals are unlikely to cause remarkable disbiosis in microbiota as these are part of a routine diet and mild perturbations, even they happen, can be restored by probiotics. Identification of the nature of active ingredient as well as mechanism of action of traditional medicines would be the requirements for research in future.

\section{References}

Ahmad K, Farahmand F, Najafi M and Shoaran M 2013 Probiotics for the treatment of Pediatric Helicobacter pylori infection: A randomized double blind clinical trial. Iranial J. Pediat. 23 79-84

Amieva MR and El-Omar EM 2008 Host-bacterial interactions in Helicobacter pylori infection. Gastroenterology 134 306-323 
Appelmelk BJ, Smit IS, Negrini R, Moran AP, Aspinall GO, Forte JG, De-Vries T, Quan H et al. 1996 Potential role of molecular mimicry between Helicobacter pylori lipopolysaccharide and host Lewis blood group antigens in autoimmunity. Infect. Immun. 64 2031-2040

Appelmelk BJ and Vandenbroucke-Grauls CMJE $2000 \mathrm{H}$. pylori and Lewis antigens. Gut 47 10-11

Bai Y, Li LR, Wang JD, Chen Y, Jin JF, Zhang ZS, Zhou DY and Zhang YL 2003 Expression of Helicobacter pylori Hsp 60 protein and its immunogenicity. World $J$. Gastroenterol. 9 2711-2714

Backert S and Selbach M 2008 Role of type IV section in Helicobacter pylori pathogenesis. Cell. Microbiol. 10 1573-1581

Balch PA and Balch JF 2000 Prescription for Nutritional Healing (Prescription for Nutritional Healing: A Practical A-To-Z Reference to Drug-Free Remedies). 3rd Edition (Avery Publisher)

Bhatia SJ, Kochar N, Abraham P, Nair NG and Mehta AP 1989 Lactobacillus acidophilus inhibits growth of Campylobacter pylori in vitro. J. Clin. Microbiol. 27 2328-2330

Bhatt AP, Redinbo MR and Bultman SJ 2017 The role of the microbiome in cancer development and therapy. $C A$ Cancer J. Clin. 67 326-344

Bellack NR, Koehoorn MW, Macnab YC and Morshed MG 2006 A conceptual model of water's role as a reservoir in Helicobacter pylori transmission: A review of the evidence. Epidemiol. Infect. 134 439-449

Bonnet M, Buc E, Sauvanet P, Darcha C, Dubois D, Pereira B, Déchelotte P, Bonnet R et al. 2014 Colonization of the human gut by E. coli and colorectal cancer risk. Clin. Cancer Res. 20 859-67

Bornschein J and Malfertheiner P 2014 Helicobacter pylori and gastric cancer. Dig. Dis. 32 249-264

Brown LM 2000 Helicobacter pylori: epidemiology and routes of transmission. Epidemiol. Rev. 22 283-297

Buckley M, Lacey S, Doolan A, Goodbody E and Seamans K 2018 The effect of Lactobacillus reuteri supplementation in Helicobacter pylori infection: a placebo-controlled, single-blind study. BMC Nutrition. 4. https://doi. org/10.1186/s40795-018-0257-4

Burne RA and Chen YM 2000 Bacterial ureases in inectious diseases. Microbes Infect. 2 533-542

Buti L, Spooner E, Van der Veen AG, Rappuoli R, Covacci A and Ploegh HL 2011 Helicobacter pylori cytotoxinassociated gene A (cag A) subverts the apoptosisestimating protein of $\mathrm{p} 53$ (ASPP2) tumor suppressor pathway of the host. Proc. Natl. Acad. Sci. USA 108 9238-9243

Bytzer P, Dahlerup JF, Eriksen JR, Jarbol D, Rosenstock S and Wildt S 2011 Diagnosis and treatment of Helicobacter pylori infection. Dan. Med. Bull. 58 C4271

Candela M, Turroni S, Biagi E, Carbonero F, Rampelli S, Fiorentini C and Brigidi P 2014 Inflammation and colorectal cancer, when microbiota-host mutualism breaks. World J. Gastroenterol. 20 908-922

Cañizares P, Gracia I, Gómez LA, Argila CM, Boixeda D, García A and Rafael L 2004 Allyl-thiosulfinates, the bacteriostatic compounds of garlic against Helicobacter pylori. Biotechnol. Prog. 20 397-401

Castellarin M, Warren RL, Freeman JD, Dreolini L, Krzywinski M, Strauss J, Barnes R, Watson $\mathrm{P}$ et al. 2012 Fusobacterium nucleatum infection is prevalent in human colorectal carcinoma. Genome Res. 22 299-306

Cellini L, Campli ED, Masulli M, Bartolomeo SD and Allocati N 1996 Inhibition of Helicobacter pylori by garlic extract (Allium sativum). FEMSImmunol. Microbiol. 13 273-277

Cellini L, Bartolomeo SD, Campli ED, Genovese S, Locatelli M and Giulio MD 2014 In vitro activity of Aloe vera inner gel against Helicobacter pylori strains. Lett. Appl. Microbiol. 59 43-48

Chatterjee A, Chatterjee S and Bandyopadhyay SK $2012 \mathrm{H}$. pylori-induces gastric ulcer: Pathophysiology and Herbal remedy. Int. J. Biol. Med. Res. 3 1461-1465

Chattopadhyay S, Datta S, Chowdhury A, Mukhopadhyay AK, Rajendran K, Bhattacharya SK, Douglass EB and Nair BG 2002 Virulence genes in Helicobacter pylori strains from West Bengal residents with overt $H$. pyloriassociated disease and healthy volunteers. J. Clin. Microbiol. 40 2622-2625

Chung JG, Chen GW, Wu LT, Chang HL, Lin JG, Yeh CC and Wang TF 1998 Effects of garlic compounds diallyl sulfide and diallyl disulfide on arylamine N-acetyltransferase activity in strains of Helicobacter pylori from peptic ulcer patients. Am. J. Chin. Med. 26 353-364

Coggins JR, Abell C, Evans LB, Frederickson M, Robinson DA, Roszak AW and Lapthorn AP 2003 Experiences with the shikimate-pathway enzymes as targets for rational drug design. Biochem. Soc. Trans. 31 548-552

Compare D and Nardone G 2011 Contribution of gut microbiota to colonic and extracolonic cancer development. Dig. Dis. 29 554-561

Cover TL and Blaser MJ 1992 Purification and characterization of the vacuolating toxin from Helicobacter pylori. J. Bio. Chem. 267 10570-10575

Crew KD and Neugut AI 2006 Epidemiology of gastric cancer. World J. Gastroenterol. 12 354-362. https://doi. org/10.3748/wjg.v12.i3.354

Czinn SJ and Blanchard T 2011 Vaccinating against Helicobacter pylori infection. Nat. Rev. Gastroenterol. Hepatol. 8 133-140

Darini E 2004 Gastric colonization by Helicobacter pylori associated with gene A cytotoxin (cagA): relationship with cell proliferation and apoptosis. $\mathrm{PhD}$ thesis, Universidade de São Paulo

De R, Kundu P, Swarnakar S, Ramamurthy T, Chowdhury A, Nair GB and Mukhopadhyay AK 2009 Antimicrobial activity of curcumin against Indian Helicobacter pylori 
and also during mice infection. J. Antimicrob. Agents Chemothe. 53 1592-1597

Dunne C, Murphy L, Flynn S, O’Mahony L, O’Halloran S, Feeney M, Morrissey D, Thornton G et al. 1999 Probiotics: from myth to reality. Demonstration of functionality in animal models of disease and in human clinical trials. Antonie Van Leeuwenhoek 76 279-292

Egan BJ, Katicic M, Connor HJO and Morain CAO 2007 Treatment of Helicobacter pylori. Helicobacter 12 31-37

Ernst PB and Gold BD 2000 the disease spectrum of Helicobacter pylori: the immunopathogenesis of gastroduodenal ulcer and gastric cancer. Ann. Rev. Micrbiol. 54 615-640

Evans DJ Jr, Evans DG, Engstrand L and Graham DY 1992 Urease-associated heat shock protein of Helicobacter pylori. Infect. Immun. $602125-27$

Fiorentino M, Ding H, Blanchard TG, Czinn SJ, Sztein MB and Fasano A 2013 Helicobacter pylori-induced disruption of monolayer permeability and proinflammatory cytokine secretion in polarized human gastric epithelial cells. Infect. Immun. 81 876-883

Fuller R 1992 History and development of probiotics; in Probiotics (Springer, Dordrecht) pp 1-8

Gevers D, Knight R, Petrosino JF, Huang K, McGuire AL, Birren BW, Nelson KE, White O et al. 2012 The Human Microbiome Project: A community resource for the healthy human microbiome. PLoS Biology. https://doi. org/10.1371/journal.pbio.1001377

Gilani AH and Rahman AU 2005 Trends in ethnopharmocology. J. Ethnopharmacol. 100 43-49

Gill HS and Guarner F 2004 Probiotics and human health: a clinical perspective. Postgraduate Med. J. 80 516-526

Graham DY 1991 Helicobacter pylori: Its epidemiology and its role in duodenal ulcer disease. J. Gastroenterol. Hepatol. 6 105-113

Graham DY, Malaty HM and Go MF 1994 Are there susceptible host to Helicobacter pylori infection? Scand. J. Gastroenterol. 29 6-10

Gürbüz AK, Küçükkardali Y, Yazgan Y, Ozel M and Polat T 2002 Does eradication of Helicobacter pylori infection reduce hypergastrinema during long term therapy with proton pump inhibitors? Turk. J. Gastroenterol. 13 $159-163$

Herrmann KM and Weaver LM 1999 The shikimate pathway. Annu. Rev. Plant Physiol. Plant Mol. Biol. 50 473-503

Holz C, Busjahn A, Mehling H, Arya S, Boettner M, Habibi $\mathrm{H}$ and Lang C 2015 Significant reduction in Helicobacter pylori load in humans with non-viable Lactobacillus reuteri DSM17648: A pilot study. Probiotics Antimicrob. Proteins 7 91-100

Homan M and Orel R 2015 Are probiotics useful in Helicobacter pylori eradication? World J. Gastroenterol. 21 10644-10653

Houimel M, Corthesy-Theulaz I, Fisch I, Wong C, Corthesy B, Mach J and Finnern R 2001 Selection of human single chain $\mathrm{Fv}$ antibody fragments binding and inhibiting Helicobacter pylori urease. Tumour Biol. 22 36-44

Ilver D, Arnqvist A, Ogren J, Frick IM, Kersulyte D, Incecik ET, Berg DE, Covacci A et al. 1998 Helicobacter pylori adhesin binding fucosylated histo-blood group antigens revealed by retagging. Science 279 373-377

Joo M 2017 Rare gastric lesions associated with Helicobacter pylori infection: A histopathological review. J. Pathol. Transl. Med. 51 341-251

Kalali B, Luque RM, Javaheri A and Gerhard M 2014 H. pylori Virulence factors: influence on immune system and pathology. Mediators Inflamm. https://doi.org/10.1155/ 2014/426309

Kao CY, Sheu BS and Wu JJ 2016 Helicobacter pylori infection: An overview of bacterial virulence factors and pathogenesis. Biomed. J. 39 14-23

Karpinski TM 2019 Role of oral microbiota in cancer development. Microorganisms 7. https://doi.org/10.3390/ microorganisms 7010020

Khodadad A, Farahmand F, Najafi M and Shoaran M 2013 Probiotics for the treatment of pediatric Helicobacter Pylori infection: A randomized double blind clinical trial. Iran J. Pediatr. 23 79-84

Kim HM, Lee EH, Hong SB and Shin Y 1998 Effect of Syzygium aromaticum extract on immediate hypersensitivity in rat. J. Ethnopharm. $60125-131$

Kim JM, Zheng HM, Lee BY, Lee WK and Lee DH 2013 Anti-Helicobacter pylori properties of gut gard. Prev. Nutr. Food Sci. 18 104-110

Konturek PC, Konturek SJ, Sito E, Kwiecien N, Obtulowicz W, Bielanski W and Hahn EG 2001 Luminal alpha methyl histamine stimulates gastric secretion in duodenal ulcer patients via releasing gastrin. Eur. J. Pharmacol. 301 181-192

Kuipers EJ, Peña AS, Festen HP M, Meuwissen SGM, Uyterlinde AM, Roosendaal R, Pals G and Nelis GF 1995 Long-term sequelae of Helicobacter pylori gastritis. 345. https://doi.org/10.1016/S0140-6736(95)91084-0

Kuol CH, Hsu PI, Kuo FC, Wang SS WW, Hu HM, Liu CJ, Chuah SK, Chen YH, Wul DC and Tseng HH 2013 Comparison of 10 day bismuth quadruple therapy with high-dose metronidazole or levofloxacin for second-line Helicobacter pylori therapy: a randomized controlled trial. J. Chemother. 68 222-228

Kusters JG, Vliet AH and Kuipers EJ 2006 Pathogenesis of Helicobacter pylori infection. Clin. Microbiol. Rev. 19 449-490

Kwok T, Zabler D, Urman S, Rohde M, Hartig R, Wessler S, Misselwitz R, Berger J et al. 2007 Helicobacter exploits integrin for type IV secretion and kinase activation. Nature 449 862-866

Lapenna D and Curccurollo F 1996 Hypochlorous acid and its pharmacological antagonism: an update picture. Gen. Pharmacol. 27 1145-1147

Lee A 2009 The microbiology and epidemiology of Helicobacter pylori infection. Scand. J. Gastroenterol. 29 2-6 
Lehours P, Vale FF, Bjursell MK, Melefors O, Advani R, Glavas S, Guegueniat J, Gontier E et al. 2011 Genome sequencing reveals a phage in Helicobacter pylori. MBio. https://doi.org/10.1128/mbio.00239-11

Lind TS, Veldhuyzen van SV, Zanten P, Unge R, Spiller E, Bayerdorffer CO'Morain, Bardhan KD, Bradette M, Chiba N, Wrangstadh M, Cederberg C and Idstrom JP 1996 Eradication of Helicobacter pylori using one-week triple therapies combining omeprazole with two antimicrobials the MACHI study. Helicobacter 1 138-144

Lin DM, Koskella B and Lin HC 2017 Phage therapy: An alternative to antibiotics in the age of multi-drug resistance. World J. Gastrointest. Pharmacol. Ther. 8 162-173. https://doi.org/10.4292/wjgpt.v8.i3.162

Lloyd KC and Soll AH 1994 Multiple pathways controlling acid secretion. J. Gastroenterol. 29 77-79

Lopetuso LR, Napoli M, Rizzatti G, Scaldaferri F, Franceschi F and Gasbarrini A 2018 Considering gut microbiota disturbance in the management of Helicobacter pylori infection. Expert Rev. Gastroenterol. Hepatol. 12 899-906

Losurdo G, Cubisino R, Barone M, Principi M, Leandro G, Lerardi E and Leo AD 2018 Probiotic monotherapy and Helicobacter pylori eradication: A systematic review with pooled data analysis. World J. Gastroenterol. 24 139-149

Lozupone CA, Stombaugh JI, Gordon JI, Jansson JK and Knight R 2012 Diversity, stability and resilience of the human gut microbiota. Nature 489 220-230

Lychkova AE, Tsaregorodtseva TM and Serova TI 2010 Cytokine profile during experimental gastric and duodenal ulcers: The serotonin role. Eksp. Klin. Gastroentrol. 2 37-39

Mader HJ, Szostak MP, Hensel A, Lubitz W and Haslberger AG 1997 Endotoxicity does not limit the use of bacterial ghosts as candidate vaccines. Vaccine 15 195-202

Mahdavi J, Sonén B, Hurtig M, Olfat FO, Forsberg L, Roche N, Ångström J, Larsson T et al. 2002 Helicobacter pylori SabA adhesin in persistent infection and chronic inflammation. Science 297 573-578

Mahady GB, Matsuura H and Pendland SL 2001 Allixin, a phytoalexin from garlic, inhibits the growth of Helicobacter pylori in vitro. Am. J. Gastroenterol. 96 3454-3455

O’Mahony R, Al-Khtheeri H, Weerasekera D, Fernando N, Vaira D, Holton J and Basset C 2005 Bactericidal and anti-adhesive properties of culinary and medicinal plants against Helicobacter pylori. World J. Gastroenterol. 11 7499-7507

Malfertheiner P, Venerito M and Schulz C 2018 Helicobacter pylori infection: new facts in clinical management. Curr. Treat. Options Gastroenterol. 16 605-615

Malfertheiner P, Megraud F, O'Morain CA, Atherton J, Axon AT R, Bazzoli F, Gensini GF, Gisbert JP et al. 2012 Management of Helicobacter pylori infection - the Maastricht IV/ Florence Consensus Report. Gut. 61 646-664
Marshall B 2002 Helicobacter pylori: 20 years on. Clin. Med. 2 147-152

Marshall BJ, Armistrong JA, McGechie DB and Glancy RJ 1985 Attempt to fulfill kocks postulates for pyloric Campylobacter. Med. J. Aust. 142 436-439

Mitchell HM 2001 Epidemiology of infection; in Helicobacter pylori: Physiology and Genetics (eds) HLT Mobley, GL Mendz and SL Hazell (Washington DC, ASM Press) PMID: 21290723

Montrose DC and Floch MH 2005 Probiotics used in human studies. Ali. Tract Clin. Rev. 39 469-484

Morris AJ, Ali MR, Nicholson GI, Perez GIP and Blaser MJ 1991 Long-term follow-up of voluntary ingestion of Helicobacter pylori. Ann. Internal Med. 114 662-663

Mrda Z, Zivanovic M, Rasic J, Gajin S, Somer L, Trbojevic S, Majoros J and Petrović Z 1998 Therapy of Helicobacter pylori infection using Lactobacillus acidophilus. Med. Pregl. 51 343-345

Myllyluoma E, Ahlroos T, Veijola L, Rautelin H, Tynkkynen S and Korpela R 2007 Effects of anti-Helicobacter pylori treatment and probiotic supplementation on intestinal microbiota. Int. J. Antimicrob. Agents $2967-72$

Nagahata Y, Kawakita N, Azumi Y, Numata N, Yano M and Saitoh Y 1996 Etiological involvement of helicobacter pylori in 'reflux' gastritis after gastrectomy. Am. J. Gastroenterol. 91 2130-2134

Nazrul IB, Jaripa MD, Nemai CN and Farhana A 2010 Constituents of the essential oil from leaves and buds of clove (Syzigium caryophyllatum L. Alston). Afr. J. Plant. Sci. 4 451-454

Nicholson JK, Holmes E, Kinross J, Burcelin R, Gibson G, Jia W and Pettersson S 2012 Host-gut microbiota metabolic interactions. Science 336 1262-1267

Noto JM and Peek Jr. RM 2017 The gastric microbiome, its interaction with Helicobacter pylori, and its potential role in the progression to stomach cancer. PLoS Pathog. 13 https://doi.org/10.1371/journal.ppat.1006573

Osato MS, Reddy SG and Graham DY 1999 Osmotic effect of honey on growth and viability of Helicobacter pylori. Dig. Dis. Sci. 44 462-464

Pan M, Wan C, Xie Q, Huang R, Tao X, Shah NP and Wei H 2016 Changes in gastric microbiota induced by Helicobacter pylori infection and preventive effects of Lactobacillus plantarum ZDY 2013 against such infection. J. Dairy Sci. 99 970-981

Parker JS 2016 Brain maker: the power of gut microbes to heal and protect your brain-for life. Yale J. Biol. Med. 89 423

Patel SR, Smith K, Letley DP and Gu Q 2013 Helicobacter pylori down regulates expression of human $\beta$-defensin 1 in the gastric mucosa in a type IV secretion-dependent fashion. Cell Microbiol. 15 2080-2092

Pandey R, Misra V, Misra SP, Dwivedi M, Kumar A and Tiwari BK 2010 Helicobacter pylori and gastric cancer. Asian Pac. J. Cancer Prev. 11 583-588 
Parsonnet J 1993 Helicobacter pylori and gastric cancer. Gastroenterol. Clin. N. Am. 22 89-104

Patra R, Chattopadhyay S, De R, Ganguly GM, Chowdhury A, Ramamurthy T, Nair GB and Mukhopadhyay AK 2012 Multiple infection and microdiversity among Helicobacter pylori isolates in a single host in India. PLoS One 7 e43370

Pounder RE and Ng D 1995 The prevalence of Helicobacter pylori infection in different countries. Aliment. Pharmacol. Ther. 9 33-39

Quigley EM 2013 Gut bacteria in health and diseases. Gastroenterol. Hepatol. 9 560-569

Qureshi N, Li P and Gu Q 2019 Probiotic therapy in Helicobacter pylori infection: a potential strategy against a serious pathogen? Appl. Microbiol. Biotechnol. 103 1573-1588

Rajkumar N, Shanthi G, Shantha Sheela V and Selvakumar S 2014 Antimicrobial activity of Emblica officinalis and Cayratia pedata against Helicobacter pylori. Int. J. Allied Med. Sci. Clin. Res. 2 453-458

Ranade N, Wankhede SS, Ranpise NS and Mundada MS 2012 Development of bilayer floating tablet of Amoxicillin and Aloe vera gel powder for treatment of gastric ulcers. AAPS Pharm. Sci. Tech. 13 1518-1523

Ridley RG 1998 Planting new targets for antiparasitic drugs. Nat. Med. 4 894-895

Roberts FC, Roberts W, Johnson JJ, Kyle DE, Krell T, Coggins JR, Coombs GH, Milhous W et al. 1998 Evidence for the shikimate pathway in apicomplexan parasites. Nature 393 801-805

Rokita E, Makristathis A, Hirschl AM and Rotter ML 2000 Purification of surface-associated urease from Helicobacter pylori. J. Chromatogr. 737 203-212

Rolfe RD 2000 The role of probiotic cultures in the control of gastrointestinal health. J. Nutr. 130 396S-402S

Rotimi O, Cairns A, Gray S, Moayyedi P and Dixon MF 2000 Histological identification of Helicobacter pylori: comparison of staining methods. J. Clin. Path. 53 756-759

Salama NR, Otto G, Tompkins L and Falkow S 2001 Vacuolating cytotoxin of Helicobacter pylori plays a role during colonization in a mouse model of infection. Infect. Immun. 69 730-736

Sarkar A, De R and Mukhopadhyay AK 2016 Curcumin as a potential therapeutic candidate for Helicobacter pylori associated diseases. World J. Gastroenterol. 22 2736-2748

Savage DC 1977 Microbial ecology of the gastrointestinal tract. Annu. Rev. Microbiol. 31 107-133

Schoep TD, Fulurija A, Good F, Lu W, Himbeck RP, Schwan C, Choi SS, Berg DE et al. 2010 Surface properties of Helicobacter pylori urease complex are essential for persistence. Plos One 5 https://doi.org/10. 1371/journal.pone.0015042

Schwabe RF and Jobin C 2013 The microbiome and cancer. Nat. Rev. Cancer 13 800-812.
Sears CL and Garrett WS 2014 Microbes, microbiota, and colon cancer. Cell Host Microbe 15 317-328

Sen S and Mansell TJ 2020 Yeasts as probiotics: Mechanisms, outcomes and future potential. Fungal Genet. Biol. 137 https://doi.org/10.1016/j.fgb.2020.103333

Servin AL and Coconier MH 2003 Adhesion of probiotic strains to the intestinal mucosa and interaction with pathogens. Best Pract. Res. Clin. Gastroenterol. 17 741-754

Sheh A and Fox JG 2013 The role of gastrointestinal microbiome in Helicobacter pylori pathogenesis. Gut Microbes 4 505-531

Shetty V, Lamichhane B, Chua EG, Ballal M and Tay CY 2018 Draft Genome sequences of 42 Helicobacter pylori isolates from rural regions of South India. Genome Announc. 6 https://doi.org/10.1128/genomea.01486-17

Silveira JA, Filho JES, Souza LEO, Souza LBS, Santana WJ and Coutinho HDM 2005 Virulence factors and epidemiologic traits of Helicobacter pylori. Rev. Med. Ana. Costa. $11-10$

Sivam GP, Lampe JW, Ulness B, Swanzy SR and Potter JD 1997 Helicobacter pylori in vitro susceptibility to garlic (Allium sativum) extract. Nutr. Cancer 27 118-121

Smith SM 2014 Role of Toll-like receptors in Helicobacter pylori infection and immunity. World J. Gastrointest. Pathophysiol. 5 133-146

Somal N, Coley KE, Molan PC and Hancock BM 1994 Susceptibility of Helicobacter pylori to the antibacterial activity of manuka honey. J. R. Soc. Med. 87 9-12

Song HY, Long Z, Liu DY, Yao XJ and Li Y 2018 What role do probitics play in the eradication of Helicobacter pylori? Current knowledge and ongoing research. Gastroenterol. Res. Pract. https://doi.org/10.1155/2018/ 9379480

Stefano K, Marco M, Federica G, Laura B, Barbara B, Gioacchino L, Francesco di M and Gian LA 2018. Helicobacter pylori, transmission routes and recurrence of infection: state of the art. Acta Biomed. $8972-76$

Suerbaum S and Josenhans C 2007 Helicobacter pylori evolution and phenotypic diversification in a changing host. Nat. Rev. Microbiol. 5 441-452

Suvarna VC and Boby VU 2005 Probiotics in human health: A current assessment. Curr. Sci. 88 1744-1748

Suzuki H, Seto K, Mori M, Suzuki M, Miura S and Ishii H 1998 Monochloramine induced DNA fragmentation in gastric cell line MKN45. Am. J. Physiol. Renal Physiol. $275712-716$

Takeuchi H, Trang VT, Morimoto N, Nishida Y, Matsumura $\mathrm{Y}$ and Suigura T 2014 Natural products and food components with anti-Helicobacter pylori activities. World J. Gastroenterol. 20 8971-8979

Talley NJ, Phung N and Kalantar JS 2001 Indigestion: When is it functional? Brit. Med. J. 323 1294-1297

Taylor DE and Sherburne R 1995 Helicobacter pylori expresses a complex surface carbohydrate, Lewis X. Am. Soc. Microbiol. $634564-4568$ 
Torres ME 2017 Parasite guest relationship: normal human flora. http://www.higiene.edu.uy/cefa/Libro2002/Cap\% 2013.pdf

Tozun N and Vardareli E 2016 Gut microbiome and gastrointestinal cancer: Les liaisons Dangereuses. J. Clin. Gastroenterol. 50 191-196

Turnbaugh PJ, Ley RE, Hamady M, Liggett CMF, Knight R and Gordon JI 2007 The human microbiome project. Nature 449 804-810

Uchiyama J, Takeuchi H, Kato S, Takemura-Uchiyama I, Ujihara T, Daibata M and Matsuzaki S 2012 Complete genome sequences of two Helicobacter pylori bacteriophages isolated from Japanese patients. J. Virol. 86 11400-11401

Vale FF and Oleastro M 2014 Overview of the phytomedicine approaches against Helicobacter pylori. World J. Gastroenterol. 20 5594-5609

Vale FF, Alves Matos AP, Carvalho P and Vitor JM 2008 Helicobacter pylori phage screening. Microsc. Microanal. 3 150-151

Velin D and Michetti P 2006 Immunology of Helicobacter pylori infection. Digestion 73 116-123

Vitor JMB and Vale FF 2011 Alternative therapies for Helicobacter pylori: probiotics and phytomedicine. FEMS Immunol. Med. Microbiol. 63 153-164

Wang YC 2014 Medicinal plant activity on Helicobacter related diseases. World J. Gastroenrol. 20 10368-10382

Warren JR and Marshall BJ 1983 Unidentified curved bacilli on gastric epithelium in active chronic gastritis. Lancet. 1 1273-1275

Warren JR and Marshall BJ 1984 Unidentified curved bacilli in the stomach of patients with gastritis and peptic ulceration. The Lancet 323 1311-1315
Weeks DL and Sachs G 2001 Sites of $\mathrm{pH}$ regulation of the urea channel of Helicobacter pylori. Mol Microbiol. 40 1249-1259

Wu W, Yang Y and Sung G 2012 Recent insights into antibiotic resistance in Helicobacter pylori eradication. Gastroenterol. Res. Pract. 2012 1-9

Yamaguchi H, Osaki T, Taguchi H, Hanawa T, Yamamoto T and Kamiya S 1998 Relationship between expression of HSP60, urease activity, production of vacuolating toxin, and adherence activity of Helicobacter pylori. J. Gastroenterol. 10 6-9

Yamamura K, Baba Y, Nakagawa S, Mima K, Miyake K, Nakamura K, Sawayama H, Kinoshita K et al. 2016 Human microbiome Fusobacterium nucleatum in esophageal cancer tissue is associated with prognosis. Clin. Cancer Res. 22 5574-5581

Yap TWC, Gan HM, Lee YP, Leow AHR, Azmi AN, Francois F, Perez GIP, Loke MF et al. 2016 Helicobacter pylori eradication causes perturbation of the human gut microbiome in young adults. PLoS One 11 e0151893

Zaidi SF and Sugiyama T 2013 Antibacterial and antiinflammatory effects of medicinal plants or spices against Helicobacter pylori: A review. Helicobacter. Res. 17 430-436

Zaidi SF, Yamada K, Kadowaki M, Usmanghani K and Sugiyama T 2009 Bactericidal activity of medicinal plants, employed for the treatment of gastrointestinal ailments, against Helicobacter pylori. J. Ethnopharmacol. 21 286-291

Zaidi SF 2016 Helicobacter pylori associated Asian enigma: Does diet deserve distinction? World J. Gastrointest. Oncol. 8 341-350 